\title{
A low damage and ductile rocking timber wall with passive energy dissipation devices
}

Article in Earthquakes and Structures · August 2015

DOI: $10.12989 /$ eas.2015.9.1.000

3 authors, including:

Wei Yuen Loo

UNITEC Institute of Technology

14 PUBLICATIONS 61 CITATIONS

SEE PROFILE
Nawawi Chouw

University of Auckland

199 PUBLICATIONS 1,340 CITATIONS

SEE PROFILE 


\title{
A low damage and ductile rocking timber wall with passive energy dissipation devices
}

\author{
Wei Yuen Loo*, Pierre Quenneville ${ }^{a}$ and Nawawi Chouw ${ }^{b}$ \\ Department of Civil and Environmental Engineering, Faculty of Engineering, \\ The University of Auckland, 20 Symonds St, Auckland, New Zealand
}

(Received June 22, 2014, Revised November 20, 2014, Accepted December 7, 2014)

\begin{abstract}
In conventional seismic design, structures are assumed to be fixed at the base. To reduce the impact of earthquake loading, while at the same time providing an economically feasible structure, minor damage is tolerated in the form of controlled plastic hinging at predefined locations in the structure. Uplift is traditionally not permitted because of concerns that it would lead to collapse. However, observations of damage to structures that have been through major earthquakes reveal that partial and temporary uplift of structures can be beneficial in many cases. Allowing a structure to move as a rigid body is in fact one way to limit activated seismic forces that could lead to severe inelastic deformations. To further reduce the induced seismic energy, slip-friction connectors could be installed to act both as hold-downs resisting overturning and as contributors to structural damping. This paper reviews recent research on the concept, with a focus on timber shear walls. A novel approach used to achieve the desired sliding threshold in the slip-friction connectors is described. The wall uplifts when this threshold is reached, thereby imparting ductility to the structure. To resist base shear an innovative shear key was developed. Recent research confirms that the proposed system of timber wall, shear key, and slip-friction connectors, are feasible as a ductile and lowdamage structural solution. Additional numerical studies explore the interaction between vertical load and slip-friction connector strength, and how this influences both the energy dissipation and self-centring capabilities of the rocking structure.
\end{abstract}

Keywords: damage avoidance; energy dissipation; rocking structure; slip-friction; timber shear walls

\section{Introduction}

Conventional earthquake resistant structures are designed with the intention that the structure is fixed at its base during an earthquake, and that ductile behaviour that limits activated forces on the structure is achieved through inelastic deformations at certain locations, or in certain elements within the structure, while the main members are expected to remain fully elastic. The problem with this approach is that while life safety is generally assured, the structure is typically damaged to an irrecoverable degree. However recent years has seen increasing interest in the philosophy of

*Corresponding author, Ph.D. Candidate, E-mail: wloo002@aucklanduni.ac.nz

a Professor, E-mail: p.quenneville@auckland.ac.nz

${ }^{\mathrm{b}}$ Associate Professor, E-mail: n.chouw@ auckland.ac.nz 
(a)

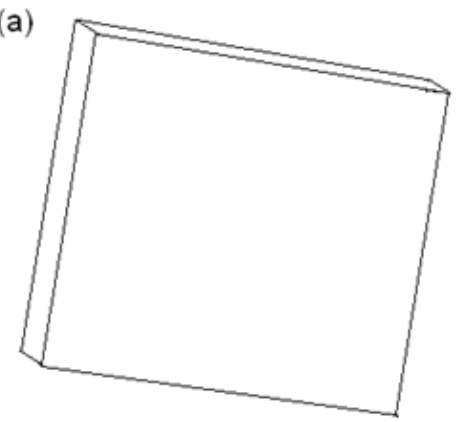

(b)

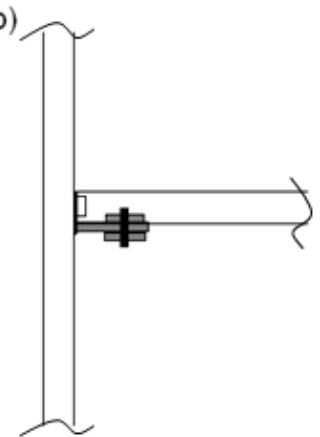

(c)

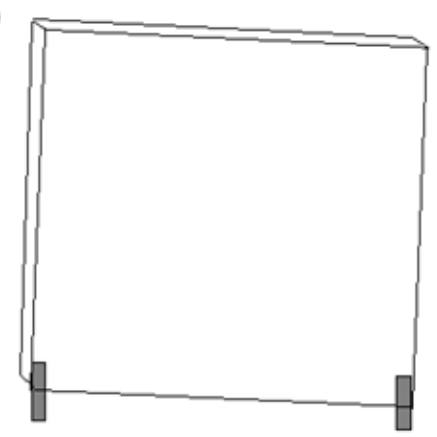

Fig. 1 (a) Free rocking block, (b) Slip-friction connector originally developed for use in steel frames, and (c) the rocking block concept combined with slip-friction connectors

damage avoidance. The main principle behind this approach is to allow global non-linear behaviour and ductile behaviour of a structure, but without material damage. One of the ways this can be achieved is through allowing a structure to uplift and rock when a certain overturning moment has been attained (see Fig. 1(a)) (Housner (1963) reported on the benefits of partial and temporary uplift in terms of the survival of slender elevated water tanks during the Chilean earthquakes of 1960, and the stability of free-standing stone columns in India during an earthquake.) Another way is to implement passive energy dissipation devices such as slip-friction connectors in a structure (see Fig. 1(b)), thereby providing the desired ductility, and capping activated forces on the structure.

This paper covers recent research on combining the benefits of these two quite dissimilar approaches into one concept (see Fig. 1(c)), but with a particular focus on how timber structures can benefit.

\section{Background}

\subsection{Wood shear walls}

One common type of wood shear wall is of plywood sheathing nailed to framing. For timber structures in general ductility is achieved through the ductile steel connections, and in the case of timber shear walls ductile behaviour is specifically achieved through the deformation of the nail connections (Buchanan 2007). Because this deformation invariably involves brittle damage to the wood through which a laterally deforming nail passes, the behaviour of the connections is highly 'pinched', and it is widely observed and accepted that the behaviour of sheathing to framing shear walls is governed mainly by the behaviour of the nail connections (Foliente 1995). Loo et al. (2012a) presented a way of modelling the nail behaviour using simple elements readily available in most finite element packages. An example of the response of a model nail is shown in Fig. 2(a). These nails were implemented in model walls, and Fig. 2(b) shows how the behaviour of a single nail connection is reflected in the overall behaviour of the wall, while Fig. 2(c) shows the force time-history of the wall under cyclic loading.

Because of the highly pinched nature of the hysteresis loops, energy dissipation potential can be considered to be only moderately efficient. Usually the ultimate strength, $F_{u l t}$, is around twice 

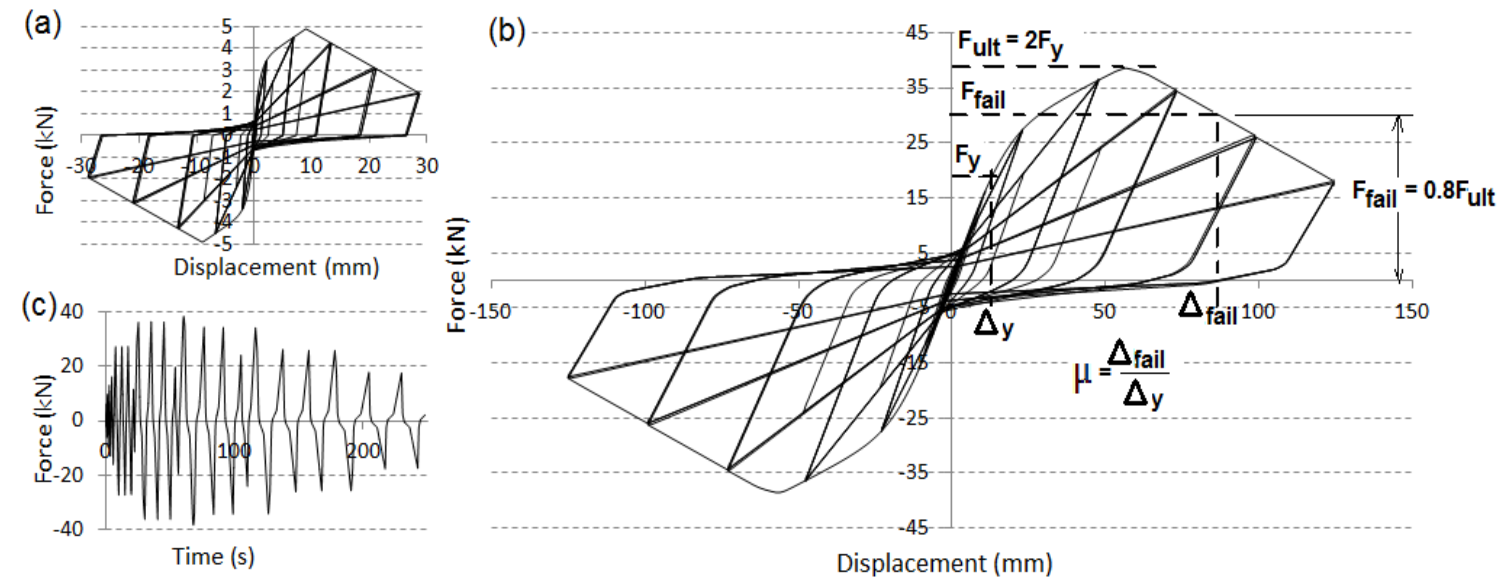

Fig. 2 Numerically obtained results for sheathing to framing wood walls: (a) Hysteretic behaviour of single nail connection, (b) hysteretic behaviour of a model wall incorporating the nail connections, and (c) force time history of the wall

the yield strength, $F_{y}$. The ductility, $\mu$, is rather arbitrarily calculated, with the failure displacement, $\Delta_{\text {fail }}$, divided by the yield displacement, $\Delta_{y}$, where failure is that point where the force has declined to $80 \%$ of the value of peak strength (see Fig. 2(b)) (Loo et al. 2012b).

In recent years walls of solid engineered lumber panels have seen increasing use. These are typically of laminated veneer lumber (LVL) or cross laminated timber (CLT). The panels in themselves have tremendous strength and stiffness, and ductility is achieved through allowing deformation of the steel angle brackets used for the shear key and hold-down connectors, and the nails and screws attaching them to the wall panels (Shen et al. 2013). Thus similar to the case for sheathing-to-framing walls, the hysteretic behaviour is highly pinched (Popovski and Karacabeyli 2012), and energy dissipation is similarly not efficient. Earthquake induced damage is likewise permanent.

From the above discussion, it is apparent that timber walls have the potential for improved behaviour in terms of the following:

- Energy dissipation.

- Avoidance of material and connection damage through reliably capping activated seismic forces below a desired level.

- Re-centring capability.

- Reduction in over-strength requirement in capacity design i.e., members are currently designed to remain elastic for actions associated with twice the yield level of the structure.

Structural movability and the use of supplemental energy dissipation are possible ways of improving performance and it is these concepts that are addressed in this paper.

\subsection{Structural moveablility}

Movability refers to that part of the displacement of a structure that is not due to deformations caused by stresses and their corresponding strains within a structure. In civil structures this typically refers to uplift and/or rocking caused by the overturning moment just exceeding the resisting moment. For freely rocking blocks the resisting moment is provided by gravity. Housner 
(1963) investigated the free oscillations of rocking blocks that were similar in geometry but different in size, and showed that there was a surprising scale effect in which the larger blocks demonstrated greater stability than the smaller blocks. Makris and Konstantinidis (2002) compared the rocking response of slender rigid blocks with the vibration of SDOF oscillators and concluded that the dynamics of rocking structures, particularly those of smaller, less slender blocks, were not analogous to that of some SDOF substitute structure. ElGawady et al. (2010) carried out experimental work on rigid rocking blocks with different materials at the interface, where impact occurs between the wall and its supporting foundation. It was found that rubber provided the most efficient dissipation of energy, followed by concrete and timber. Acikgoz and DeJong (2012) extended the understanding of rocking structures by including the elastic oscillations of the structure itself (theretofore considered to be entirely rigid). Qin et al. (2013), has demonstrated the influence of the nonlinear behaviour of the soils under a rotating foundation, and how this can reduce the ductility demand on the structure itself. Kelly (2009) proposed a tentative design procedure for rocking multi-storey structures in which a substitute structure approach was taken. The maximum displacements found from this approach aligned closely with the displacements obtained from sophisticated nonlinear analyses.

While structural movability through free rocking can be used to effectively limit the activated seismic forces on a structure, damping can only occur when the base of the structure impacts its foundation. Another drawback with free rocking is the designer is limited to levels of overturning resistance that are gravity determined only. To address these and other issues, researchers at the University of Canterbury and at the University of Auckland have developed an approach where overturning restraint is provided mainly by post-tensioned cables running internal to and up the height of a pair of coupled LVL shear walls. Instead of simply relying on radiation damping (that is damping from impact between structure and foundation), energy dissipation is achieved largely through the provision of small U-shaped flexural plates between adjacent walls. Devereux et al. (2011) describes the first implementation of this particular type of damage avoidance structure, in the three storey NMIT Arts and Media Building in Nelson, New Zealand. Twidgen et al. (2012) has further investigated the use of post-tensioning, but in rocking precast concrete walls - however this work is still in the experimental stage.

\subsection{Passive energy dissipation}

Passive energy dissipaters as opposed to active or semi-active dissipaters require little if any long term inspection maintenance, do not require an external power supply, do not require a continuous energy source, and are simple and economical to fabricate (Butterworth 2000). The most common type of passive energy dissipation device is the slip-friction connector (also known as the slotted-bolt connector). Popov et al. (1995) conducted a suite of tests on connectors in symmetric sliding, in which the load on the centre plate is resisted equally by the two external plates. It was found that while mild-steel sliding against mild-steel produced erratic and uneven sliding behaviour, including a thin brass shim between the sliding surfaces improved behaviour significantly. Clifton et al. (2007) adopted an asymmetric connector (where external load is applied to the centre plate and only one of the external plates) for use in steel-moment frames, and Khoo et al. (2012) further advanced the concept, replacing the expensive and difficult to procure brass shims with shims of abrasion resistant steel. Clifton and Khoo's concept has seen implementation in steel buildings in New Zealand. For symmetric connectors, Loo et al. (2014a) tested connectors with no shims at all, in which the centre plate was that of abrasion resistant steel 


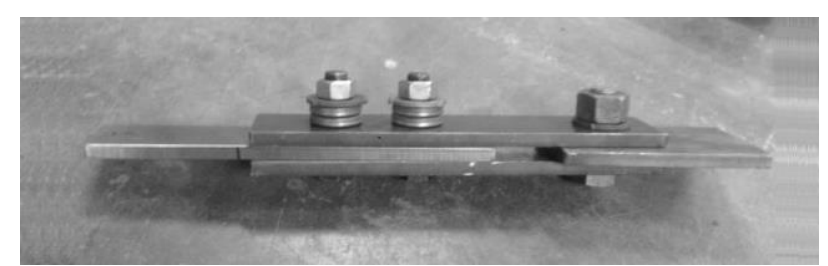

Fig. 3 Symmetric slip-friction connector as designed and fabricated by Loo et al. (2014a), with centre plate of abrasion resistant Bisalloy 400, and external plates of grade 350 mild steel. Belleville washers are used to achieve and maintain preload in the bolts

(Bisalloy 400) and the external plates were of mild steel, with the centre plate sliding directly against the external plates (see Fig. 3). The results were highly elasto-plastic square shaped loops with the configuration not only simpler than that of Popov et al. (1995), given that shims are not required, but with the added advantage of avoiding galvanic corrosion between materials that are significantly different in terms of their metallurgy.

\subsection{Combining structural movability with energy dissipating friction devices}

In order to improve the behaviour of a rocking structure, Loo et al. (2012b) proposed the use of symmetric slip-friction connectors as hold-downs for upliftable timber walls. Uplift and rocking occurs when the friction generated force threshold, $F_{\text {slip }}$, in the connectors is overcome, and through moment equilibrium the maximum activated base shear (or racking force) on a single wall panel is capped. Loo et al. (2012b) carried out a numerical investigation on flexible timber shear walls with slip-friction connectors. Nail connections were modelled from plastic multi-linear links, using the methodology described in that article. The hysteretic behaviour typical of nail connections was modelled using a pivot type hysteretic model available in SAP2000, with parameters adjusted to provide the required pinching characteristics. Numerical simulations were first carried out on a model wall with rigid hold down connectors, using an ISO97 quasi-static displacement time history schedule. The numerical hysteretic behaviour was found to accurately simulate the behaviour of the wall's actual equivalent, with the pinched behaviour of the nail connections being reflected in similarly shaped hysteretic loops for the wall (see Fig. 2(a) and 2(b)). The modelling of a slip-friction connector using an assemblage of multi-linear plastic, hook, and gap elements is then described. The model slip-friction connectors were implemented as holddown connectors, replacing the traditionally used rigid connectors. An ISO97 quasi-static displacement schedule was again applied to these walls, and the hysteretic loops were transformed from the highly pinched, to a shape very close to the elasto-plastic ideal. The degree of elastoplasticity was a function of the slot-length provided for sliding within the slip-friction connector thus the level of ductility able to be achieved was essentially unlimited, bounded only by the amount of slip that a designer would choose to allow. Further the ductile behaviour was achieved with negligible damage to the wall members and the sheathing to framing nail connections (compare with that of the wall with rigid traditional connectors, where ductility is essentially a function of nail inelastic deformability). With slip-friction connectors, energy dissipation was improved dramatically - under the same displacement time history, the wall with ductility of $\mu=6$ dissipated almost 1.7 times the energy of the same wall with traditional connectors. Walls designed for intermediate (Type C) soil conditions in Hamilton NZ, were then modelled. 
(a)

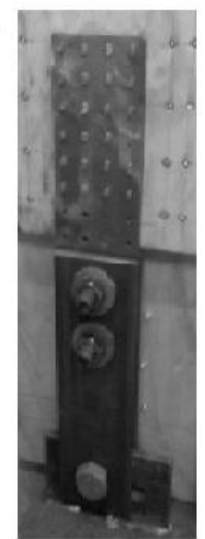

(b)

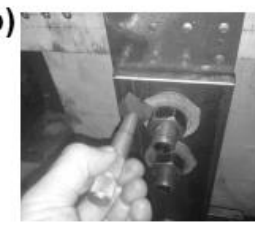

(c)

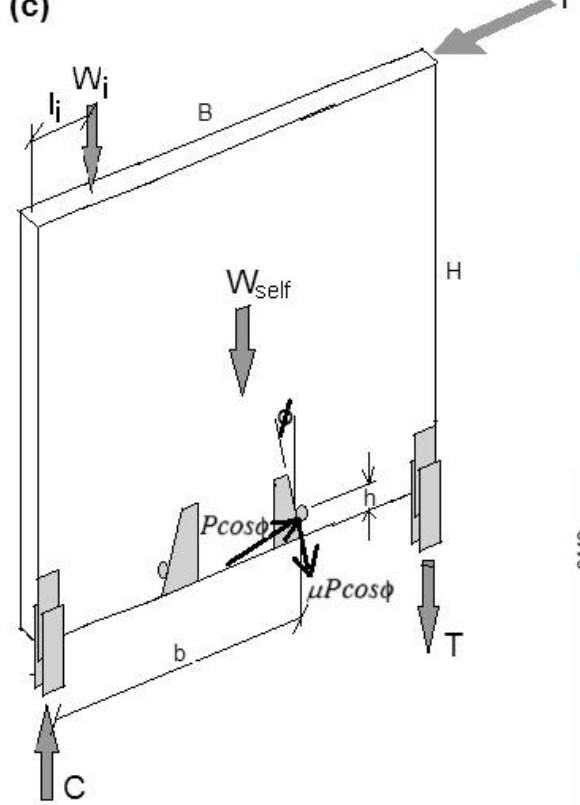

(d)

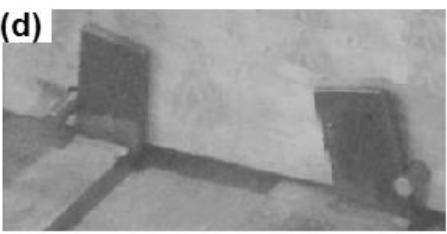

(e)

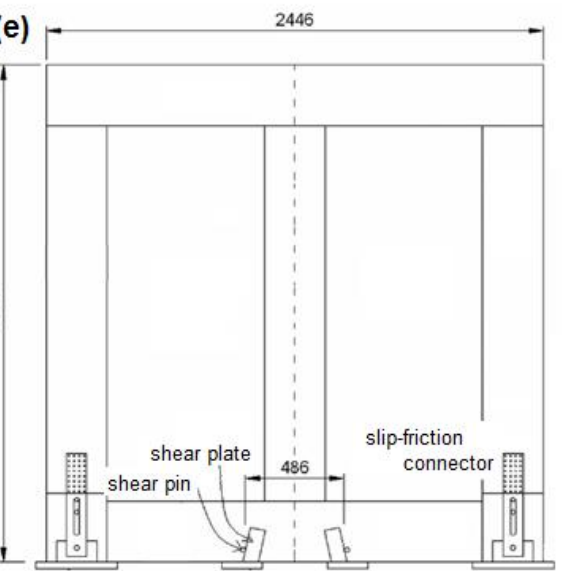

Fig. 4 (a) Slip-friction connector riveted to wall, (b) adjusting preload in the bolts, (c) forces and mobilised reactions on wall, (d) shear key, and (e) general layout of shear key and slip-friction connectors

Earthquake records were scaled to match the ULS and MCE spectrums for this location and soil type. As expected the walls with slip-friction connectors suffered little, if any damage, even under MCE scaled simulations, and drifts were generally within code mandated limits. Most importantly, the residual drifts were in general exceedingly low, even under just self-weight as the restoring mechanism - obviously this attests to the self-centring capability of the system.

In order to verify some of the promising results of the numerical study, a $2.44 \mathrm{~m}$ by $2.44 \mathrm{~m}$ experimental wall was fabricated and fitted with slip-friction connectors. The following discussion describes the concept of the proposed low-damage and ductile solution. The experiments sketched in Fig. 4 are reported in detail by Loo et al. (2014b), and the reader is referred to that article for a comprehensive account of the experiments. The $2.44 \mathrm{~m} \times 2.44 \mathrm{~m}$ wall was fabricated from two panels, each $1.22 \mathrm{~m}$ wide by $2.44 \mathrm{~m}$ high. Screws were used to join the panels, and the result was a single wall unit that was essentially rigid in nature. Slip-friction connectors were attached to the wall with riveted connections (see Fig. 4(a)). The rivets provide a rigid connection and have a very high strength to connected area ratio. The design procedure adopted was that invented by Zarnani and Quenneville (2014a, b).

In order to set the required slip-threshold, a novel technique was used, in which the preload in the bolts was varied, and this was done through varying the height of a stack of Belleville washers, and measuring this height with a depth micrometre (see Fig. 4(b)). From Loo et al. (2014b) the slip-threshold is a function of the tension in the bolts, $T_{b}$

$$
F_{\text {slip }}=n_{s} n_{b} T_{b} \mu
$$

where $n_{s}$ is the number of faying surfaces (two in this case), $n_{b}$ the number of bolts (also two), and 
$\mu$ the coefficient of friction (around 0.4 according to Loo et al. 2014a). An expression was then derived by Loo et al. (2014b) for the required height of the stack as a function of the required bolt tension, $T_{b}$

$$
h_{T b}=\left(n_{\text {parallel }} t+\delta_{\text {flat }}\right) n_{\text {series }}-\frac{T_{b}}{n_{\text {parallel }} P_{\text {flat }}} n_{\text {series }} \delta_{\text {flat }}
$$

where $n_{\text {parallel }}$ is the number of washers in parallel, $n_{\text {series }}$ the number in series, $t$ the thickness of a single washer, $P_{\text {flat }}$ the force required to deflect a single washer to the flat position, and $\delta_{\text {flat }}$ the distance to the flat position of a washer. Accuracy in setting the preload in the tension bolts will naturally mean that any difference between the strengths of the two connectors at opposite ends of the wall is minimized. This is important because Loo et al. (2014b) demonstrates that only where the difference in strength between the two connectors is less than the total gravity loading on the wall will the wall be capable of descending at one end, while uplifting at the other - a capability without which re-centring would not be possible

$$
\left|F_{\text {slip.left }}-F_{\text {slip.right }}\right| \leq \sum_{i=1}^{n} W_{i}
$$

To resist base shear, a shear key consisting of two solid steel rods $25 \mathrm{~mm}$ in diameter inserted through holes near the base of the wall and placed in direct bearing against a pair of upright steel plates (on both sides of the wall), with the slope of the contact surface set at a slight angle from the vertical in order to facilitate sliding, was fabricated (see Fig. 4(d)). In order to account for the friction between the shear pin and the shear plate, and its contribution to overturning resistance, and hence wall strength, $P$, the following expressions (refer Fig. 4(c) for variable definitions) were derived. For moment resistance, Loo et al. (2014b) provides the following expression

$$
M_{r}=F_{\text {slip }} B+\frac{W_{\text {self }} B}{2}+\sum_{i=1}^{n} W_{i} l_{i}+K_{m r p} P
$$

The racking force to initiate overturning (assuming minimal frictional contribution between the base of the wall and foundation) is

$$
P=\frac{F_{\text {slip }} B+\frac{W_{\text {self }} B}{2}+\sum_{i=1}^{n} W_{i} l_{i}}{H-K_{\text {mrp }}}
$$

$K_{m r p}$ encapsulates the influence of the shear key, and is a function of its geometry and the coefficient of friction between the shear pin and shear plate (refer to Loo et al. (2014b) for the derivation)

$$
K_{m r p}=\left(h^{2}+b^{2}\right)^{1 / 2} \cos \phi\left\{\mu \cos \left(\phi-\tan ^{-1}(h / b)\right)-\sin \left(\phi-\tan ^{-1}(h / b)\right)\right\}
$$

In Loo et al. (2014b), demonstrated how variation in the angle of the shear key contact surface can have a large effect on $K_{m r p}$, and also as a consequence the contribution of the shear key to overall moment resistance. For example, for a coefficient of friction, $\mu=0.6$, increasing the angle $\varphi$ from 0 degrees to 12 degrees, decreases the impact of the shear key on moment resistance from 38 

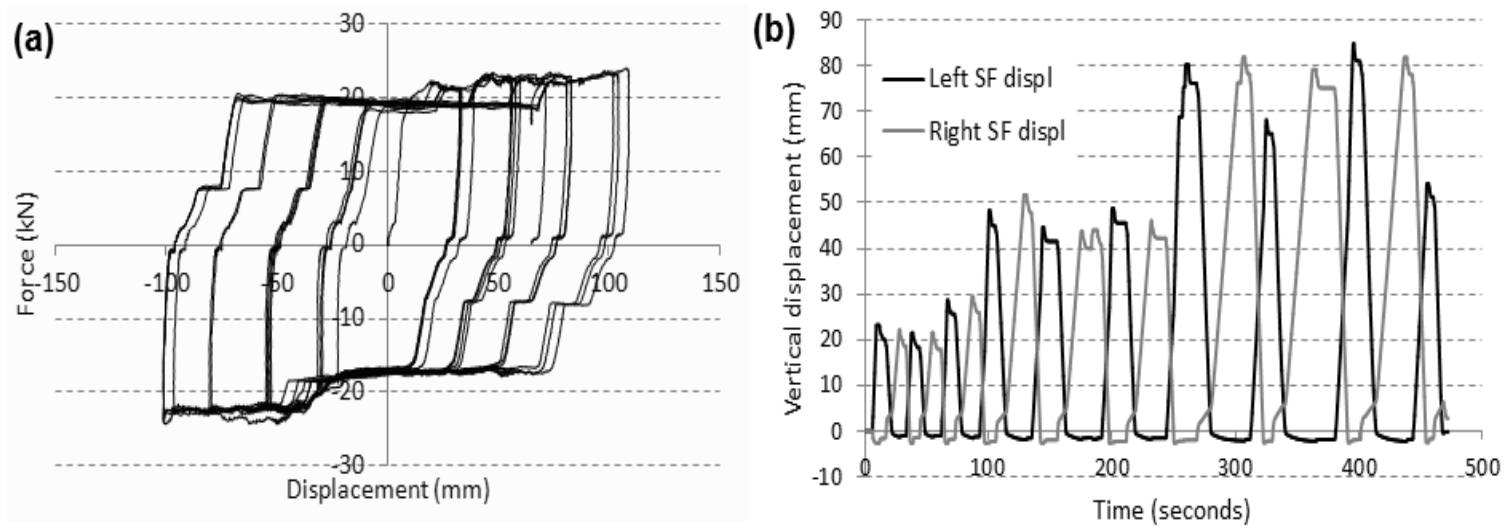

Fig. 5 Typical wall response to quasi-static hysteretic loading. (a) Hysteretic behaviour of wall and (b) vertical displacement at wall corner showing uplift at one end mobilises descent at the other

percent to 25 percent. It is noted that the frictional behaviour between the steel pin and the shear plate can be complex and erratic. However with careful selection of the configuration and layout of the shear key, and in reference to Eq. (6), the influence of erratic behaviour in the shear key on overall wall behaviour can be minimised.

The results from a series of experimental tests largely agreed with the racking force prediction from Eq. (5), and for 25 tests, with the connectors enduring more than $14 \mathrm{~m}$ of cumulative travel, and with racking strengths ranging from around $5 \mathrm{kN}$ to $60 \mathrm{kN}$, excellent elasto-plastic behaviour was observed (see Fig. 5(a)). No visible damage to the wall was observed. The wall readily descended at one end while uplifting at the other (see Fig. 5(b)), thereby confirming that the difference between slip-friction connector strengths was less than the self-weight of the wall (around $2.8 \mathrm{kN}$ ), and this attested to the precision and accuracy of the depth gauge method used to set bolt preload.

Comparing the hysteretic response of Fig. 5(a) (for a wall with slip-friction connectors) with that of Fig. 2(b) (wall with traditional rigid connectors), it is clear that combining movability with passive energy dissipation devices has the following advantages:

- Through adjusting the preload in the bolts, the mobilisation of friction can be varied and in turn the activated base shear capped below a certain level.

- Because the behaviour of the wall is governed by the behaviour of the hold-down connectors, the overall behaviour is close to the elasto-plastic ideal.

- As long as the components of the wall are designed to remain elastic for loads up to the maximum activated base shear, damage will be avoided.

- Because the yield strength of the wall is governed by the sliding threshold in the connectors, and this threshold is predictable, the amount of over-strength to be adopted in the capacity design of the elastic components is expected to be much smaller than the currently used value of around two (for walls with traditional connectors $F_{u l t}$ is around twice $F_{y}$ ).

- With minimal gravity loading, there is the potential for excellent re-centring behaviour, provided the slip-force in the connectors can be set to levels close to each other.

The following section discusses some results from a numerical study on the influence of vertical load and slip-friction connector strength on the energy dissipation capability of a wall system. 
(a)

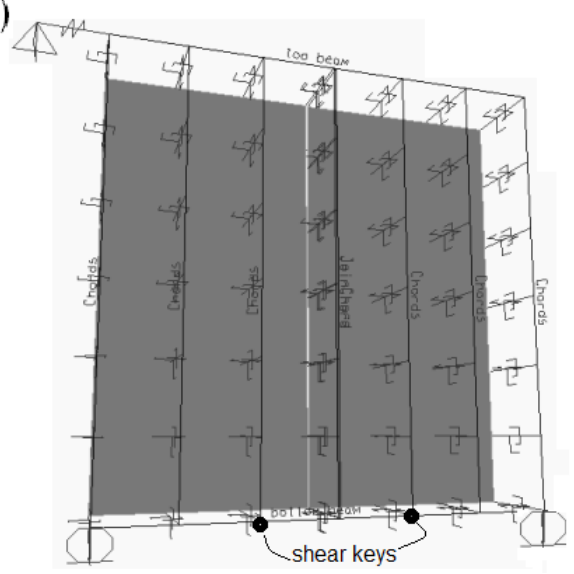

(b)

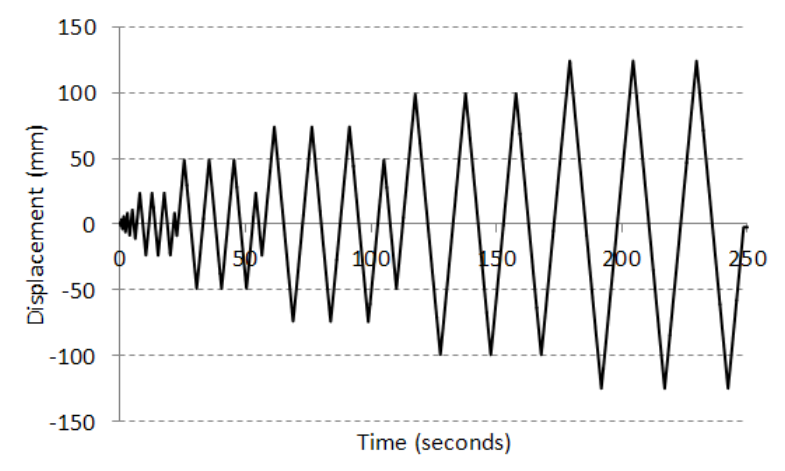

Fig. 6 Numerical wall model: (a) Exploded view and (b) displacement schedule

\section{Energy dissipation and re-centring capability - influence of gravity vs. slip-force}

\subsection{Numerical model and test matrix}

In order to explore the energy dissipation characteristics of walls with slip-friction connectors, a $2.44 \times 2.44 \mathrm{~m}$ sheathing to framing shear wall was numerically modelled in SAP2000 (2009), in the manner described by Loo et al. (2012a, b). The sheathing was modelled as $12 \mathrm{~mm}$ thick F11 grade plywood. For the framing studs, $38 \mathrm{~mm} \times 89 \mathrm{~mm}$ Spruce Pine Fir with an MOE of $9500 \mathrm{MPa}$ and density of $420 \mathrm{~kg} / \mathrm{m}^{3}$ were used. Studs were spaced at $406 \mathrm{~mm}$. The top beam was represented by a steel beam (consistent with experimental conditions in tests by Varoglu et al. (2006)). One nail element was used to represent the behaviour of four actual nails, each of yield strength $750 \mathrm{~N}$. The model wall is shown in Fig. 6(a), and the cyclic load protocol applied to the wall is shown in Fig. 6(b).

While admittedly the shear-keys in the numerical model of Fig. 6(a) are an imperfect representation of an actual shear-key, the approximation of the hysteretic behaviour of an actual shear wall will be reasonable, provided the shear key plates are sufficiently inclined, to minimise any erratic frictional effects, and situated sufficiently distant from the centre of the wall in order to facilitate re-centring. The experimental result of Fig. 5(a) demonstrates the near perfect elastoplastic behaviour that can be obtained when these criteria are adhered to.

The maximum horizontal displacement applied to the top corner of the wall was $125 \mathrm{~mm}$. The wall was designed with a yield strength of $13.1 \mathrm{kN}$, and an ultimate strength of $26.2 \mathrm{kN}$ (twice the yield strength). The displacement at yield, $\delta_{y}$, was around $10 \mathrm{~mm}$. Slip-friction connectors were modelled using gap, hook, and multilinear-plastic elements, as described by Loo et al. (2012b). The slot length was set to allow a maximum upward displacement of $40 \mathrm{~mm}$ (thus providing a slip-friction enabled ductility, $\mu_{s f}$, of $40 \mathrm{~mm} / \delta_{y}=4$ ). This was less than the maximum uplift of 125 $\mathrm{mm}$, and was done in order to allow for an adequate demonstration of the benefits of implementing slip-friction connectors, while at the same time allowing the reader to view the effect on the wall when sliding in the connectors is prevented by the bolts of the connector impacting the slot ends.

The first test was carried out with traditional, rigid hold-down connectors. All remaining tests 
Table 1 Test matrix

\begin{tabular}{ccccc}
\hline \hline$F_{\text {slip }}(\mathrm{kN})$ & $M_{s f}(\mathrm{kNm})$ & $W_{\text {total }}(\mathrm{kN})$ & $M_{w}(\mathrm{kNm})$ & $R_{m w}=M_{w} / M_{r}$ \\
\hline 13.12 & 31.48 & 0.00 & 0.00 & 0.0 \\
11.80 & 28.33 & 2.62 & 3.15 & 0.1 \\
10.49 & 25.18 & 5.25 & 6.30 & 0.2 \\
9.18 & 22.03 & 7.87 & 9.44 & 0.3 \\
7.87 & 18.89 & 10.49 & 12.59 & 0.4 \\
6.56 & 15.74 & 13.12 & 15.74 & 0.5 \\
5.25 & 12.59 & 15.74 & 18.89 & 0.6 \\
3.93 & 9.44 & 18.36 & 22.03 & 0.7 \\
2.62 & 6.30 & 20.98 & 25.18 & 0.8 \\
\hline
\end{tabular}

Notes:

$M_{r}=F_{y} H=13.12 \mathrm{kN} \times 2.4 \mathrm{~m}=31.5 \mathrm{kNm}$

$M_{s f}=F_{s l i p} \times 2.4 \mathrm{~m}$

$M_{w}=W_{\text {total }} \times 1.2 \mathrm{~m}$

were carried out with slip-friction connectors implemented as hold-downs. A combination of slipfriction connector strength and vertical load, $W_{\text {total }}$, (including self-weight) provided the moment resistance, $M_{r} . M_{r}$ was set so the maximum activated racking force, $P$, on the wall was equal to the yield strength $F_{y}$. From moment equilibrium

$$
M_{r}=F_{y} H=M_{s f}+M_{w}=F_{\text {slip }} B+W_{\text {total }} \frac{B}{2}
$$

where $B$ is the wall width and $H$ the wall height. The moment contribution of $F_{\text {slip }}$ and $W_{\text {total }}$ to $M_{r}$ are $M_{s f}$ and $M_{w}$, respectively. These were varied in order to observe the influence of an increasing vertical load contribution to energy dissipation and re-centring capability. The ratio $R_{m w}$ is the contribution of gravity moment to the total moment resistance, $M_{r}$. In order for the maximum activated base shear to equal the yield strength, $F_{y}=13.12 \mathrm{kN}$, the total moment resistance, $M_{r}$, was $31.5 \mathrm{kNm}$ for all tests with slip-friction connectors i.e., tests 2 to 10 . The test matrix is shown in Table 1.

\subsection{Results and discussion}

The force-displacement results for tests 1 to 10 are shown in Fig. 7.

From Fig. 7, it is apparent that up to a total displacement of around $\pm 40 \mathrm{~mm}$, the slip-friction connectors cap the activated forces on the wall to the intended level. Beyond this the end of the slot in the connector prevents further sliding, and force-displacement behaviour follows the trajectory it would have continued along, but for the presence of the slip-friction connectors, and inelastic damage in incurred. There are thus two levels of ductility, one associated with uplift of the wall (i.e., the slip-friction connector enabled part, $\mu_{s f}$ ), and the other associated with the inelastic damage (mainly through deformation of the sheathing-to-nail connections). A practical implementation of the concept could have the ductility associated with uplift correspond to a ULS event (without damage), while an MCE event would potentially require the total available ductility 

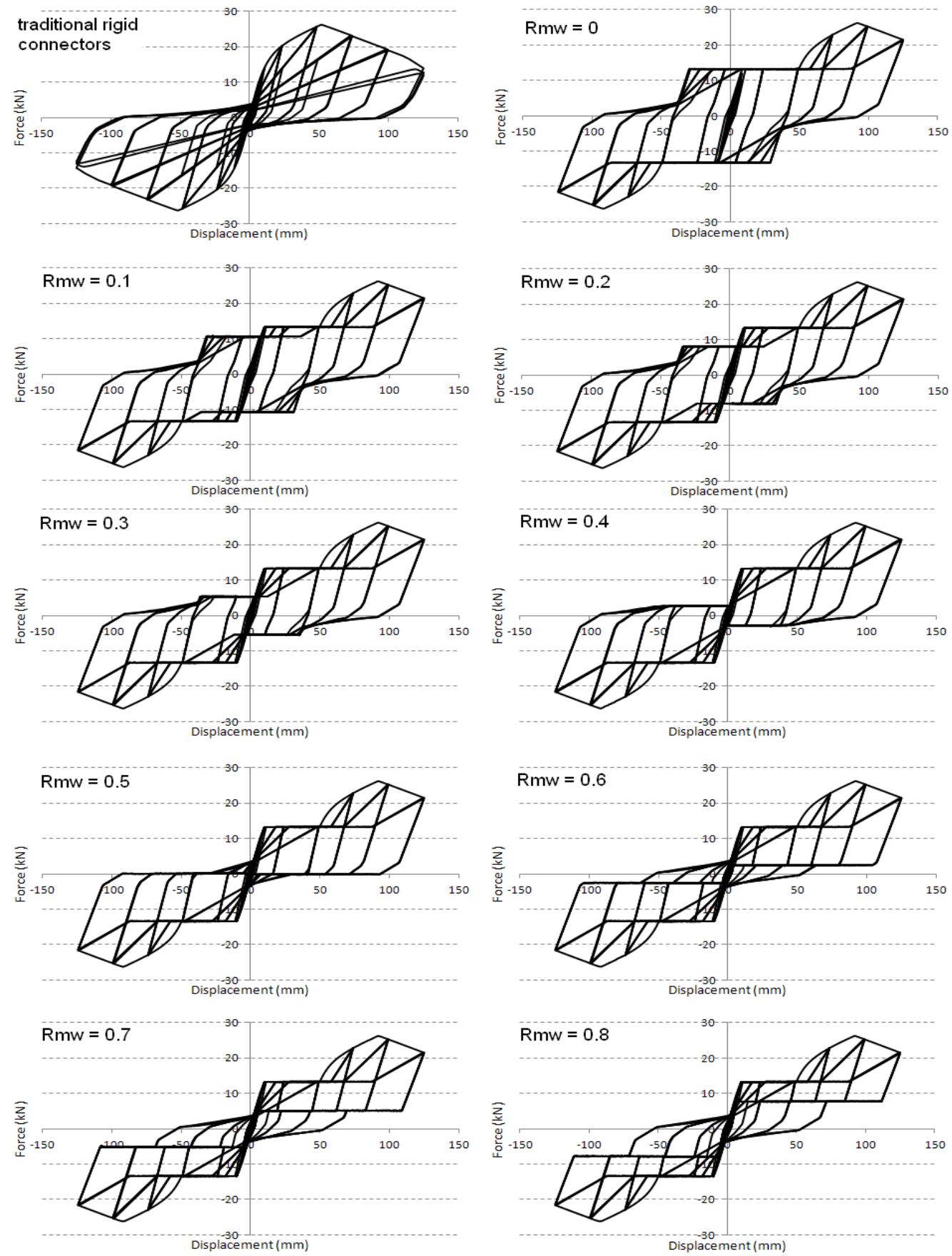

Fig. 7 Hysteretic behaviour of sheathing-to-framing wall showing influence of gravity as proportion of moment resistance. Note that the wall has a slip-friction enabled ductility level of $\mu_{s f}=4$

(with damage). Also from Fig. 7, it is observed that with the increasing influence of gravity (and a correspondingly lower slip-friction force) the hysteretic loops become vertically offset along a line 
representing the original elastic range of the walls. The vertical offsets indicate a tendency to recentre. However, with the increasing dominance of gravity and reduction of shear connector slipforce, $F_{\text {slip }}$, the energy dissipation ability of the wall system will naturally diminish. From the force and displacement time histories the energy dissipation, $E_{\text {diss }}$ from 1 to $n$ time steps, is calculated

$$
E_{\text {diss. } n}=\sum_{i=1}^{n} \frac{\left(F_{i}+F_{i-1}\right)}{2}\left(\delta_{i}-\delta_{i-1}\right)
$$

where $F_{i}$ is the measured force and $d_{i}$ the displacement at the $i^{\text {th }}$ time step, respectively. Referring to Eq. (8), it is pointed out that if during a time step, the averaged force is greater than zero, energy will be positive if the wall displaces in a positive direction and negative (and thus subtracted) if in a negative direction. Conversely, if the averaged force is less than zero, energy at a time step will be positive for displacement in a negative direction and negative for displacement in a positive direction. In this way Eq. (8) provides the area of the hysteretic loops of the force-displacement relationship. Fig. 8(a) shows the dissipated energy plotted against cumulative travel, where cumulative travel at the $n^{\text {th }}$ time step is

$$
\delta_{\text {tot. } n}=\sum_{i=1}^{n}\left|\delta_{i}-\delta_{i-1}\right|
$$

Clearly, for the displacement time-history schedule adopted, energy dissipation decreases as the contribution to moment resistance, $R_{m w}$ increases. In the case where gravity contributes around $60 \%$ to the overall moment resistance $\left(R_{m w}=0.6\right)$, the energy dissipation, for the adopted loading time history only, is essentially the same as that of the wall with the traditionally rigid hold-downs (it should be noted that the comparison, while illustrative, is not an entirely apt one, as forces on the wall with traditional connectors were in general higher than walls with slip-friction connectors, precisely due to the slip-friction connectors capping these same forces). Fig. 8(b) shows the respective contributions to the total dissipated energy of the slip-friction connectors on the one hand, and inelastic damage (mainly of the sheathing-to-framing nail connections) on the other hand. While the latter remains at more or less the same level (i.e., around 12000 and 13000 Joules), the slip-friction absorbed energy decreases with increasing influence of gravity, $R_{m w}$. Slipfriction dissipated energy was calculated from the vertical displacement time history records of both connectors as follows

$$
E_{\text {diss, frict }}=F_{\text {slip }}\left(\sum_{i=1}^{n}\left|\delta_{\text {vert }, \text { left }, i}-\delta_{\text {vert }, \text { left }, i-1}\right|+\sum_{i=1}^{n}\left|\delta_{\text {vert }, \text { right }, i}-\delta_{\text {vert }, \text { right }, i-1}\right|\right)
$$

The tests of Table 1 were then repeated, but with the wall modelled by a $45 \mathrm{~mm}$ thick LVL area section that remained elastically responding for the entire range of displacement (unlike the case for the sheathing-to-framing walls in which nonlinear behaviour was provided not only by the slipfriction connectors, but also the inelastic deformation of the wall itself). These numerical analyses were carried out to simulate the behaviour of a very stiff wall, somewhat equivalent to the experimental wall of Loo et al. (2014b). The connector slot length was adjusted to allow for an uplift of at least $125 \mathrm{~mm}$, thereby allowing the wall to rock in an unimpeded fashion. Fig. 9 shows the force-displacement results. The top-left result is for the wall with traditional rigid connectors. All other results are for walls with slip-friction connectors. 


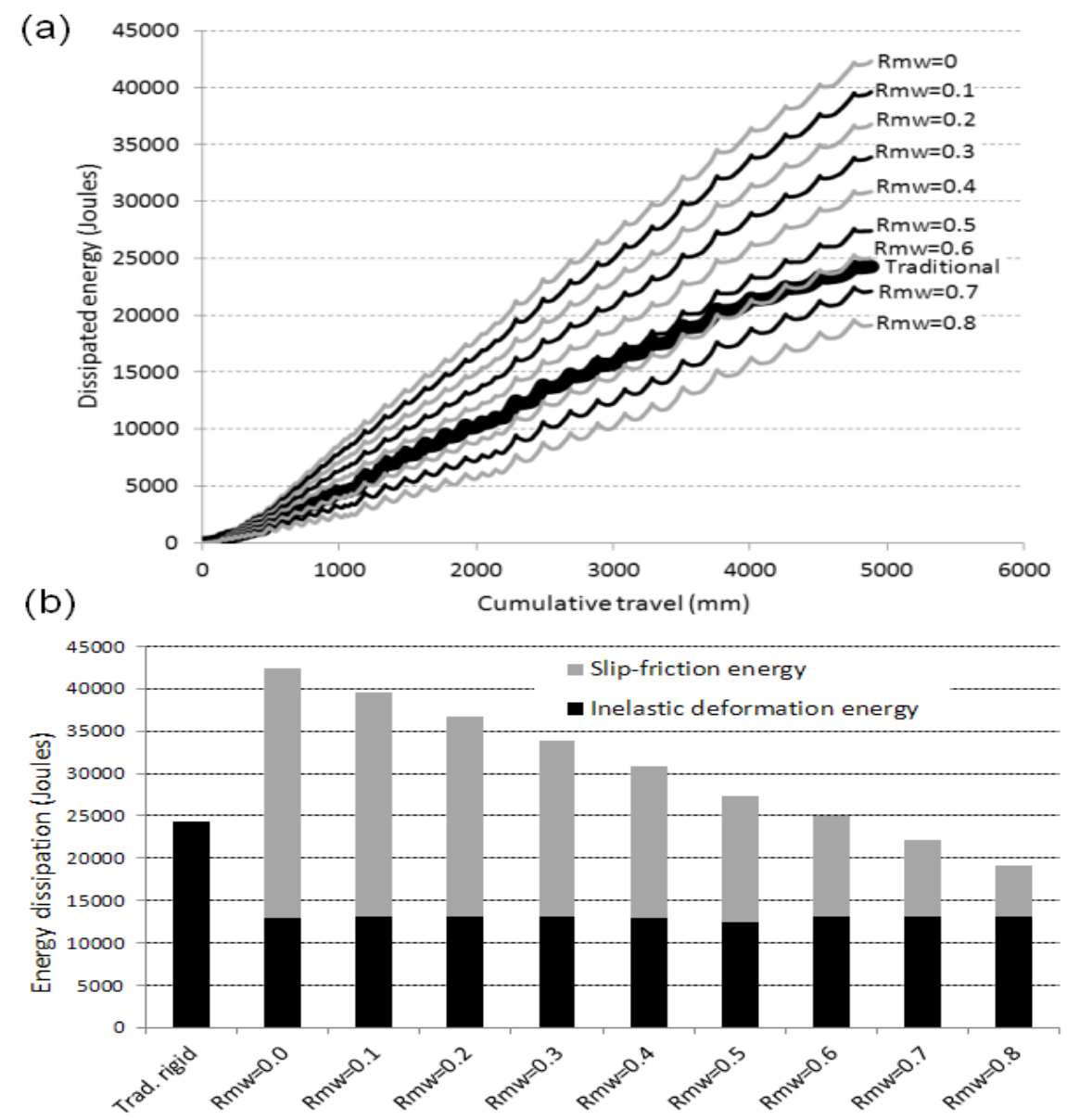

Fig. 8 Sheathing-to-framing wall. (a) Energy dissipation as a function of cumulative travel (wall with traditional connectors represented by the heavily bolded line), and (b) contribution of slipfriction connector and inelastic deformation of wall elements to energy dissipation

Compared with the results of the wall with sheathing nailed to framing (see Fig. 7), the energy dissipative characteristics almost completely reflect the behaviour of the slip-friction connectors (given that sliding is unimpeded due to long slot lengths) and the influence of gravity is clearly seen. As $R_{m w}$ increases the behaviour of the wall would tend towards that of a pure rocking block. Fig. 10(a) shows the dissipated energy as a function of cumulative travel. Note that because the wall panel itself is fully elastic responding, all the dissipated energy is due to Coulomb damping from sliding of the slip-friction connectors (Fig. 10(b)).

With zero vertical load $\left(R_{m w}=0\right)$, the wall is prone to 'climb' up the connectors, and the vertical displacement time history (recorded at the centre of the wall), with a residual displacement of around $110 \mathrm{~mm}$ is shown in Fig. 11(a). With only a small gravity contribution $\left(R_{m w}=0.1\right)$, recentring is possible (see Fig. 11(b)), as long as the strengths, $F_{\text {slip }}$, of both connectors are the same, or at least their difference in strength less than the gravity load (refer Eq. (3)). Fig. 11(b) shows displacement amplitudes at around half the horizontally applied displacements, showing that one 
end of the wall descends while the other ascends. It is emphasized that such behaviour under a controlled displacement schedule is indicative of re-centring capability only, this capability obviously increasing with $R_{m w}$ (seen from the increasingly separated hysteretic 'flags'). Under an actual earthquake loading, the wall would respond in a way unique to the acceleration record it is subjected to, with residual drifts much more likely with high values of $R_{m w}$.
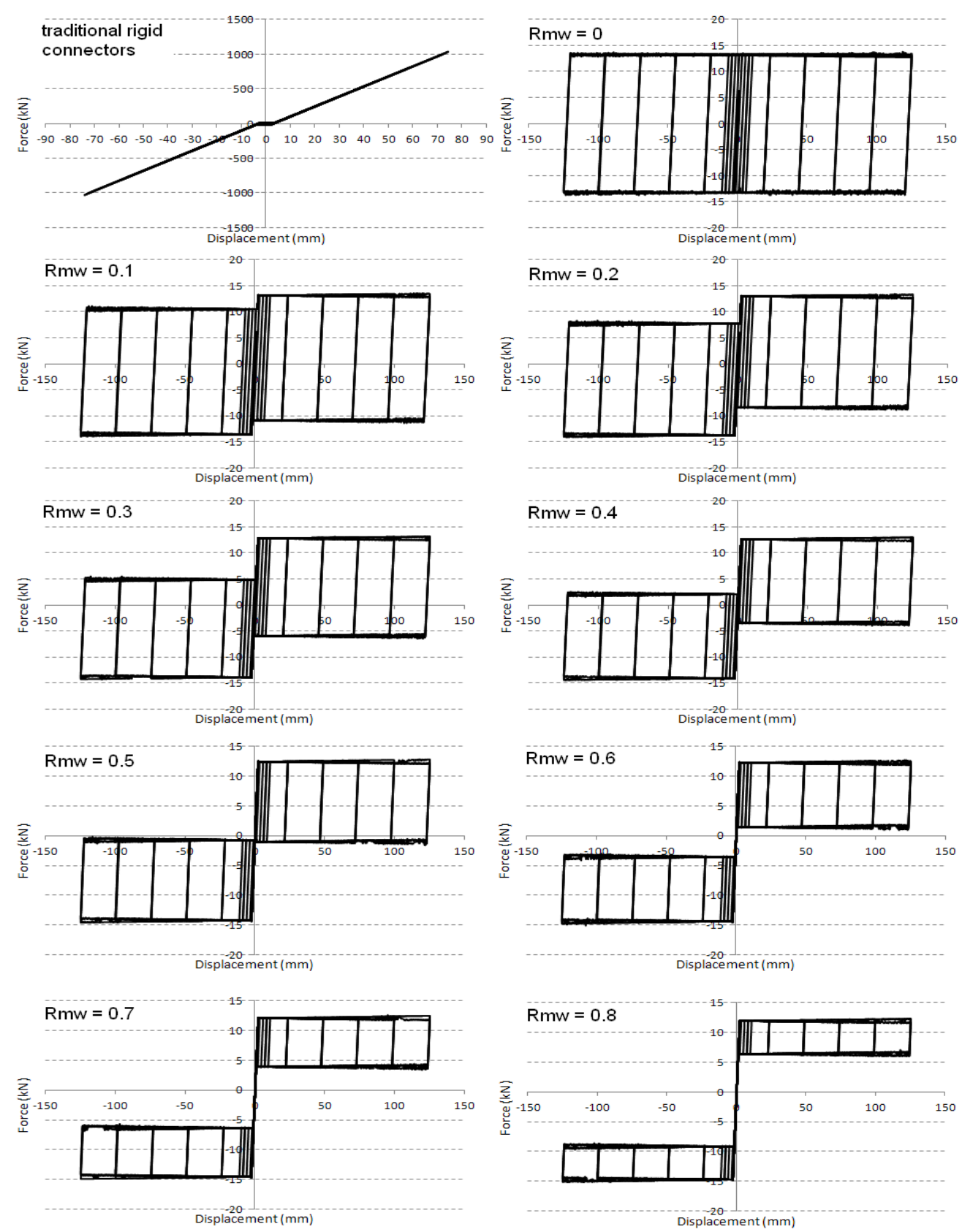

Fig. 9 Hysteretic behaviour of elastic wall showing influence of gravity as proportion of moment resistance 
(a)

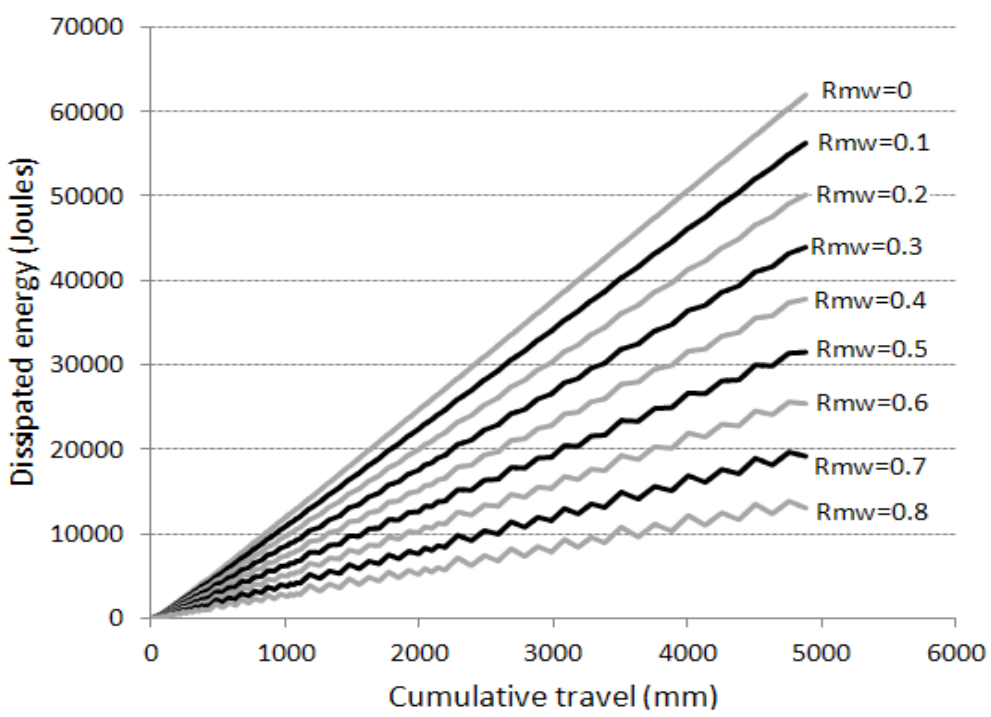

(b)

Cumulative travel $(\mathrm{mm})$

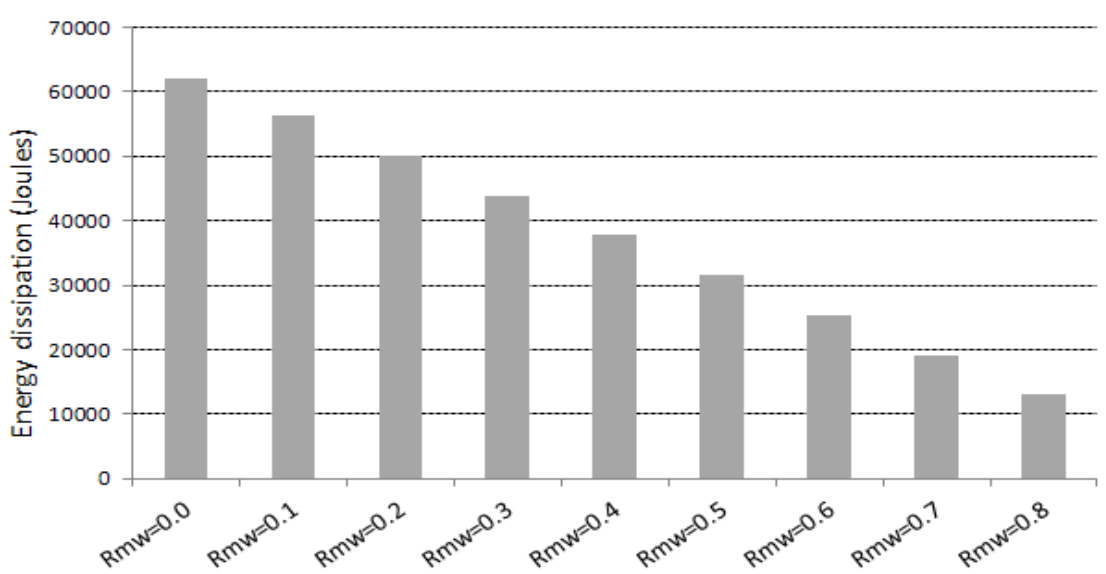

Fig. 10 Elastically responding wall. (a) Energy dissipation as a function of cumulative travel, and (b) total energy dissipation (entirely from friction)
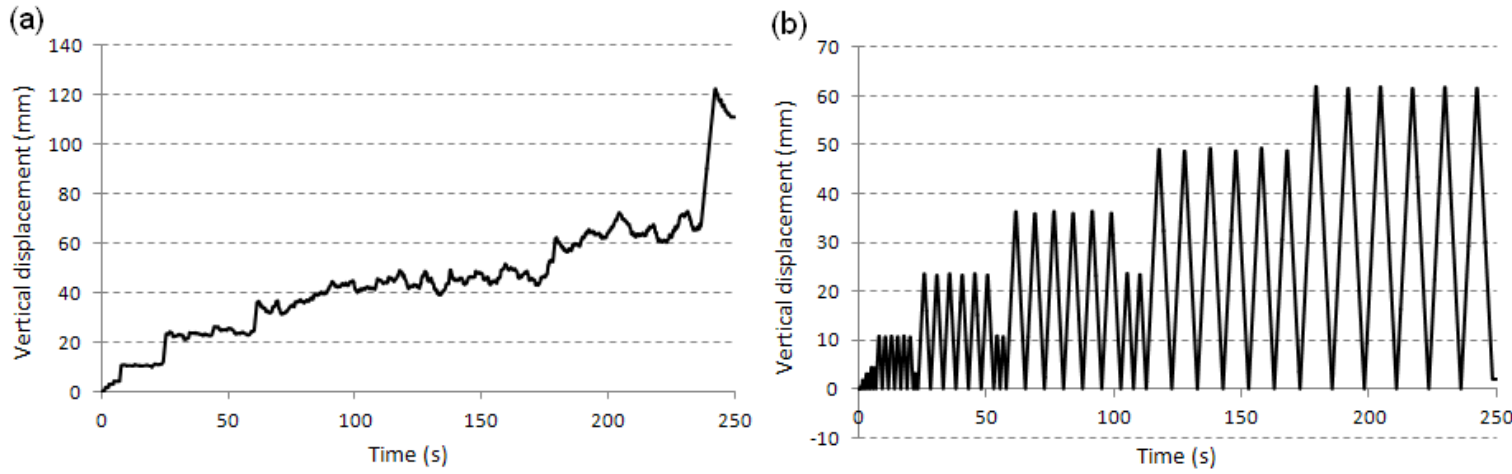

Fig. 11 Vertical displacements measured at wall centre. (a) Zero vertical load case $R_{m w}=0$, and (b) nonzero vertical load case, $R_{m w}=0.1$ and above 


\section{Conclusions}

An overview of recent research on rocking structures with passive energy dissipation, i.e., slipfriction connectors, was provided. The slip-friction connectors have a dual duty of resisting overturning moments up to a pre-determined threshold, and dissipating seismic energy. This threshold is a function of the slip-resistance of the connectors which in turn is a function of the preload in the bolts. The authors report on previous research in which the direct measurement of a stack of Belleville washers was used to achieve preload. The authors report on previous research where an experimental wall setup at the University of Auckland has confirmed previous numerical research on the effectiveness of using slip-friction connectors to avoid damage to a rocking structure.

Two types of wall were numerically modelled - one a sheathing-to-framing wall, the other a very stiff, entirely elastically responding wall. From a series of cyclic test simulations, the results confirm that a combination of slip-friction connector strength and gravity can be used to resist overturning and cap forces on the wall. As expected, a gravity dominated system demonstrates a stronger 'flagging' effect (associated with re-centring capability), while a slip-friction dominant system has superior energy dissipation characteristics.

\section{Acknowledgments}

The authors are grateful for the support of this research by the New Zealand Ministry for Primary Industries.

\section{References}

Acikgoz, S. and DeJong, M.J. (2012), "The interaction of elasticity and rocking in flexible structures allowed to uplift”, Earthq. Eng. Struct. Dyn., 41(15), $2177-2194$.

Buchanan, A. (2007), Timber design guide, 3rd edition, Timber Industry Federation Inc., Wellington, New Zealand.

Butterworth, J.W. (2000), "Ductile concentrically braced frames using slotted bolted joints", J. Struct. Eng. Soc. NZ., 13(1), 39-48.

Clifton, G.C., MacRae, H., Mackinven, S., Pampanin, S. and Butterworth, J. (2007), "Sliding hinge joints and subassemblies for steel moment frames", Proceedings of the New Zealand Society for Earthquake Engineering Conference, Palmerston North, New Zealand.

Devereux, C.P., Holden, T.J., Buchanan, A.H. and Pampanin, S. (2011), "NMIT Arts \& Media Building damage mitigation using post-tensioned timber walls", Proceedings of the Ninth Pacific Conference on Earthquake Engineering, Auckland, New Zealand.

ElGawady, M.A., Ma, Q., Butterworth, J.W. and Ingham, J. (2010), "Effects of interface material on the performance of free rocking blocks", Earthq. Eng. Struct. Dyn., 40(4), 375-392.

Foliente, G.C. (1995), "Hysteresis modelling of wood joints and structural systems", J. Struct. Eng., 121(6), 1013-1021.

Housner, G.W. (1963), “The behaviour of inverted pendulum structures during earthquakes”, Bull. Seismol. Soc. Am., 53(2), 403-417.

Kelly, T. (2009), "Tentative seismic design guidelines for rocking structures", Bull. NZ. Soc. Earthq. Eng., 42(4), 239-274.

Khoo, H.H., Clifton, G.C., Butterworth, J.W., MacRae, G. and Ferguson, G. (2012), "Influence of steel shim 
hardness on the Sliding Hinge Joint performance", J. Constr. Steel Res., 72, 119-129.

Loo, W.Y., Quenneville, P. and Chouw, N. (2012a), "A numerical approach for simulating the behaviour of timber shear walls", Struct. Eng. Mech., 42(3), 383-407.

Loo, W.Y., Quenneville, P. and Chouw, N. (2012b), "A numerical study of the seismic behaviour of timber shear walls with slip-friction connectors", Eng. Struct., 34(22), 233-243.

Loo, W.Y., Quenneville, P. and Chouw, N. (2014a), "A new type of symmetric slip-friction connector", $J$. Constr. Steel Res., 94, 11-22.

Loo, W.Y., Kun, C., Quenneville, P. and Chouw, N. (2014b), "Experimental testing of a rocking timber shear wall with slip-friction connectors", Earthq. Eng. Struct. Dyn., doi: 10.1002/eqe.2413.

Makris, N. and Konstantinidis, D. (2002), "The rocking spectrum and the limitations of practical design methodologies”, Earthq. Eng. Struct. Dyn., 32(2), 265-289.

Popov, E., Grigorian, C. and Yang, T. (1995), "Developments in seismic structural analysis and design", Eng. Struct., 17(3), 187-197.

Popovski, M. and Karacabeyli, E. (2012), "Seismic behaviour of cross-laminated timber structures", Proceedings of the World Conference on Timber Engineering, Auckland, New Zealand.

Qin, X., Chen, Y. and Chouw, N. (2013), "Effect of uplift and soil nonlinearity on plastic hinge development and induced vibrations in structures", Adv. Struct. Eng., 16(1), 135-147.

SAP2000 v14 (2009), Integrated solution for structural analysis and design, Computers and Structures, Inc., California, Berkeley.

Shen, Y-L., Schneider, J., Tesfamariam, S., Steimer, S. and Mu, Z-G. (2012), "Hysteresis behavior of bracket connection in cross-laminated-timber shear walls", Eng. Struct., 48, 980-991.

Twigden, K.M., Henry, R.S. and Ma, Q.T. (2012), "Dynamic testing of post-tensioned rocking walls", Proceedings of the 15th World Conference on Earthquake Engineering, Lisbon, Portugal.

Varoglu, E., Karacabeyli, E., Stiemer, S. and Ni, C. (2006), "Midply wood shear wall system: Concept and performance in static and cyclic testing", J. Struct. Eng., 132(9), 1417-1425.

Zarnani, P. and Quenneville, P. (2014a), "Strength of timber connections under potential failure modes - An improved design procedure", Constr. Build. Mater., 60, 81-90.

Zarnani, P. and Quenneville, P. (2014b), "Wood block tear-out resistance and failure modes of timber rivet connections - a stiffness-based approach", J. Struct. Eng., 140(2), 04013055.

$C C$ 